\title{
Effect of the Support on Structure of the Multi-Walled Carbon Nanotubes Grown By CCVD over Nickel Nanoparticles
}

\author{
N. V. Lemesh, P. E. Strizhak \\ L.V. Pisarzhevskiy Institute of Physical Chemistry of National Academy of Sciences of Ukraine, \\ Kyiv, Ukraine \\ Email: lemeshnataliia@gmail.com
}

\begin{abstract}
Effect of the support and preparation method of the $\mathrm{Ni} / \mathrm{CaO}$ and $\mathrm{Ni} / \mathrm{CaCO}_{3}$ impregnated catalysts on the morphology, diameters and growth mechanisms of the MWCNTs grown from ethylene by CCVD synthesis were studied. It was found that the interactions between the support and Ni nanoparticles in both cases are mainly weak and the growth mechanism of the majority of the carbon nanotubes is the "tip-growth". The structure of the nanotubes produced using different catalysts was, however, significantly different. Use of the $\mathrm{Ni} / \mathrm{CaO}$ catalyst results in the formation of two types of the MWCNTs on the basis of the diameters. At the $\mathrm{Ni} / \mathrm{CaCO}_{3}$, the formation of the MWCNTs and chain-like carbons fibers was observed. The differences in the morphology and diameters related to the distinct chemical transformation of the support and active phase of the catalyst during the catalyst preparation and reduction, as well as during synthesis of the nanotubes.
\end{abstract}

Keywords: Multi-walled carbon nanotubes, support, diameter distribution, morphology, nickel nanoparticles.

\section{Introduction}

Multi-walled carbon nanotubes (MWCNTs) have unique and superior chemical, physical, and mechanical properties, which attracted wide attentions of researchers for the last two decades $[1,2]$. Among the three main methods for MWCNT synthesis, catalytic chemical vapor deposition (CCVD) has been widely used to synthesize MWCNTs because of the flexible control of reaction parameters (carbon source feedstock/concentration, reaction temperature, pressure etc.) [3-5]. The type of the catalyst, method of preparation and chemical nature of the support are the main factors that affect the quantity and quality of MWCNTs produced by CCVD. Nickel, iron, and cobalt deposited on different supports such as Zeolite $[6,7], \mathrm{Al}_{2} \mathrm{O}_{3}[8], \mathrm{SiO}_{2}[9], \mathrm{MgO}[10,11]$ by coprecipitation and impregnation methods are the most common catalysts for MWCNTs growth by CCVD. However, the $\mathrm{CaO}[12]$ and $\mathrm{CaCO}_{3}[13]$ supports are not used often.

It is known that the substrate can interact both physically and chemically with the catalyst particle and consequently control the size of the metal catalyst particle [14, 15]. The size of the catalyst nanoparticles, in turn, determines the diameter of the nanotubes [16]. There are two well-known major mechanisms of MWCNTs growth. Both mechanisms consist of the steps of molecular adsorption and decomposition of the carbon-containing precursor on the catalytically-active face of the catalyst nanoparticle and the diffusion of carbon atoms through it ("tip-growth") or along the nanoparticle surface ("base-growth") [16]. In the case of the "base-growth" mechanism, the catalyst remains anchored to the substrate. On the contrary, the growth follows a "tip-growth" mechanism when the particle lifts off the substrate and is observed at the top of the MWCNTs. While a weak contact between the support and metal nanoparticle favors the "tip-growth" mechanism, a strong interaction promotes "base-growth" [17, 18].

The aim of this work is to study the effect of the chemical nature of the support and their interaction with the active phase of the $\mathrm{Ni} / \mathrm{CaO}$ and $\mathrm{Ni} / \mathrm{CaCO}_{3}$ impregnated catalysts on the morphology, diameters and growth mechanisms of the MWCNTs grown from the ethylene by the CCVD synthesis. 


\section{$2 \quad$ Experimental}

\subsection{Catalyst Preparation}

The $\mathrm{Ni} / \mathrm{CaO}$ catalyst was prepared by mixing $0.2 \mathrm{M}$ aqueous solution of $\mathrm{Ni}\left(\mathrm{NO}_{3}\right)_{2} \cdot 6 \mathrm{H}_{2} \mathrm{O}$ with $20 \%$ aqueous suspension of $\mathrm{CaO}$. The mixture was stirred and dried at room temperature, then ground to a fine powder.

The $\mathrm{Ni} / \mathrm{CaCO}_{3}$ catalyst was prepared by adding $0.94 \mathrm{M}$ aqueous solution of $\mathrm{Ni}\left(\mathrm{NO}_{3}\right)_{2} \cdot 6 \mathrm{H}_{2} \mathrm{O}$ to $\mathrm{CaCO}_{3}$ powder. The resulting mixture was dried and calcinated at $400{ }^{\circ} \mathrm{C}$ for 10 hours. The obtained mass was also ground to a homogeneous powder.

\subsection{Carbon Nanotubes Synthesis}

$0.2 \mathrm{~g}$ of the catalyst was placed in a quartz boat which was loaded in the quartz reactor tube with the diameter of $25 \mathrm{~mm}$ and a length of $90 \mathrm{~mm}$. The reactor was heated to $700{ }^{\circ} \mathrm{C}$ in a flow of hydrogen diluted with argon $\left(35 \%\right.$ vol. $\mathrm{H}_{2}, 65 \%$ vol. Ar) with a heating rate of $5{ }^{\circ} \mathrm{C} / \mathrm{min}$. After reaching the desired temperature ethylene was fed in the gas mixture ( $10 \%$ vol.). The gas flow rate was equal to 700 $\mathrm{ml} / \mathrm{min}$. The synthesis was carried out for 30 minutes, after which the reactor was cooled to room temperature in a stream of argon. After that, the quartz boat with the resulting carbon material was removed from the reactor.

Reduction of the catalysts for the analysis of their structure was performed under the same conditions, but without the addition of the ethylene to the gas mixture.

\subsection{Characterization of Mwcnts Grown On Ni/Cao Catalyst}

The structure of synthesized carbon nanotubes and catalysts before and after reduction were characterized by transmission electron microscopy (TEM), scanning electron microscopy (SEM) and Xray diffraction (XRD). TEM analysis was carried out on PEM-125K to study the microstructure of the samples. The analysis of MWCNTs by SEM microscopy was performed at the FEI NOVA NANOSEM200. For TEM analysis the samples were frayed in a mortar with alcohol obtained powder was applied to a copper mesh coated carbon film, which is placed under a microscope. For each sample, 10 TEMmicrographs were taken and the MWCNTs distributions of external and internal diameters were determined.

Information on the crystal structure of the catalysts was ascertained by XRD performed using a Bruker D8 Advance with $\mathrm{Cu} \mathrm{K \alpha}$ at $\lambda=1.54 \AA$. XRD patterns were recorded over a range of $2 \ominus$ angles from $10^{\circ}$ to $70^{\circ}$. The X-ray data were analyzed using the EVA software.

\section{$3 \quad$ Results and Discussion}

\section{1 $\mathrm{Ni} / \mathrm{CaO}$ Catalyst}

\section{Characterization of the Catalyst}

Fig. 1 shows the diffraction pattern of the catalyst $\mathrm{Ni} / \mathrm{CaO}$ before and after reduction. By using the EVA software, the representative peaks for different crystal phases were identified in the XRD spectra. It was found that the catalyst $\mathrm{Ni} / \mathrm{CaO}$ before reduction (curve 1) contains a phase of $\mathrm{Ca}(\mathrm{OH})_{2}(2 \theta=18$, $\left.29,34,47,51,54,63^{\circ}\right)$ and $\mathrm{CaCO}_{3}\left(2 \theta=23,29,3639,43\right.$ and $\left.49^{\circ}\right)$ that probably were formed due to $\mathrm{CaO}$ in the air and in aqueous solution. The diffraction peaks at $2 \theta=32,37,54$ and $65^{\circ}$ (curve 2) are related to the $\mathrm{CaO}$ obtained by decomposition of the calcium hydroxide and calcium carbonate during the reduction of the catalyst. From the x-ray diffraction pattern of the reduced catalyst, the presence of the traces of $\mathrm{Ca}(\mathrm{OH})_{2}\left(2 \theta=18,34,51,54\right.$ and $\left.55^{\circ}\right)$ was also observed indicating the surface hydration of $\mathrm{CaO}$ after reduction [122]. 


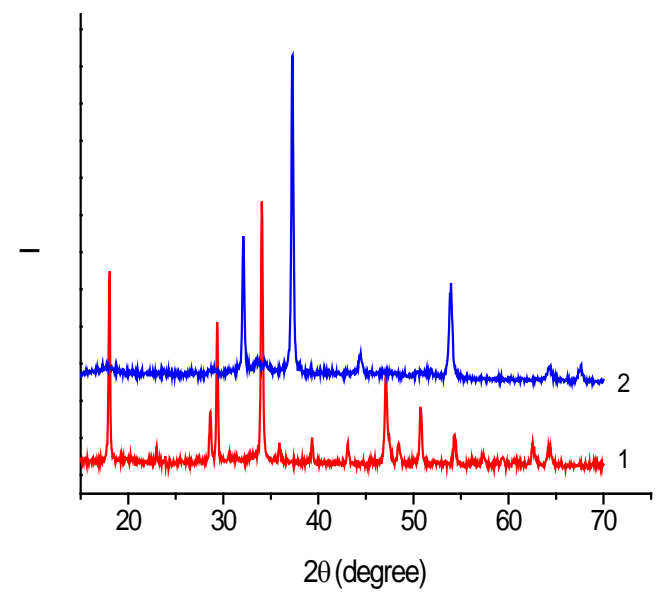

Figure 1. XRD patterns of $\mathrm{Ni} / \mathrm{CaO}$ catalyst before (1) and after (2) reduction.

The peaks at angles $2 \ominus=31,35,38,45-47^{\circ}$ on the curve 1 correspond to the nickel nitrate. The nickel nitrate decomposes and reduces to the metallic nickel under the reducing conditions. The presence of metallic $\mathrm{Ni}$ is indicated by the peaks at $2 \theta=44^{\mathrm{O}}$ and $52^{\circ}$ (curve 2). Thus, the reduction of the $\mathrm{Ni} / \mathrm{CaO}$ catalyst results in the conversion of the nickel nitrate to the metallic nickel and removal of the calcium carbonate and calcium hydroxide from the surface of $\mathrm{CaO}$. The crystallite sizes of the phases in the $\mathrm{Ni} / \mathrm{CaO}$ catalyst obtained from the EVA software curve fitting were summarized in Table 1. It was found that the size of the support particles decreased after reduction. The size of the Ni crystallites was identified as $20 \mathrm{~nm}$.

Table 1. Crystallite sizes of phases obtained by the EVA software for $\mathrm{Ni} / \mathrm{CaO}$ catalyst before and after reduction.

\begin{tabular}{lccc}
\hline \multicolumn{2}{l}{ Before reduction } & \multicolumn{2}{c}{ After reduction } \\
\hline Phase & Size $(\mathrm{nm})$ & Phase & \multicolumn{2}{l}{ Size $(\mathrm{nm})$} \\
\hline $\mathrm{Ni}\left(\mathrm{NO}_{3}\right)_{2}$ & - & $\mathrm{Ni}$ & 20 \\
$\mathrm{CaCO}_{3}$ & $31-43$ & $\mathrm{CaO}$ & $23-36$ \\
$\mathrm{Ca}(\mathrm{OH})_{2}$ & & & \\
\hline
\end{tabular}

The morphology of the $\mathrm{Ni} / \mathrm{CaO}$ catalyst nanoparticles before and after reduction were characterized using TEM and the results were shown in Fig. 2a, c. The histograms of the size distribution of the catalyst nanoparticles were drawn and presented in Fig. 2b, d. To determine the size distributions, more than 200 nanoparticles per sample were selected and their sizes were measured from their respective TEM images.

Fig. 2a displays the mixture of nanoparticles as spots of the different sizes and brightness. Their shape is close to the spherical and most of them are agglomerated. The dark spherical spots correspond to the nanoparticles and their agglomerates which were classified as nanoparticles of nickel nitrate because their electron density is large [19]. The bright spots were attributed to the nanoparticles of support respectively. 


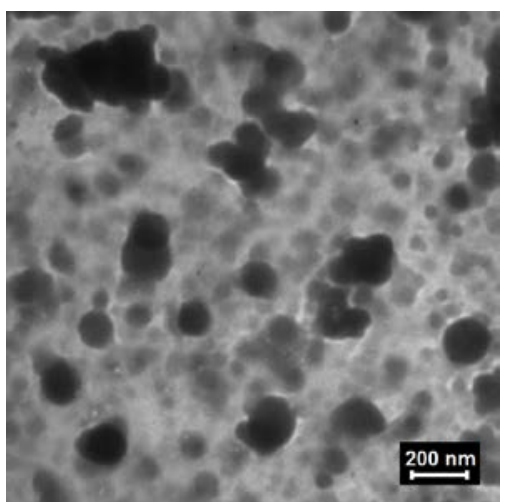

(a)

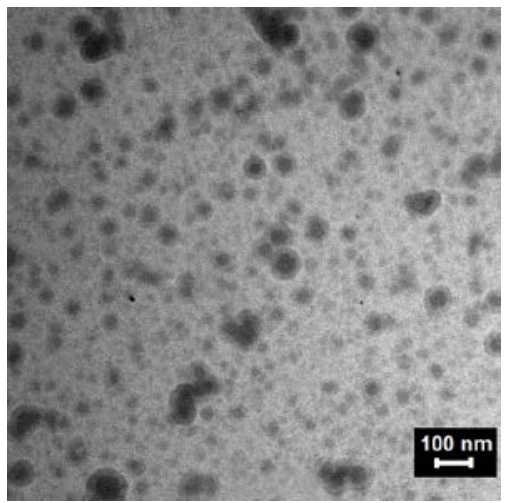

(c)

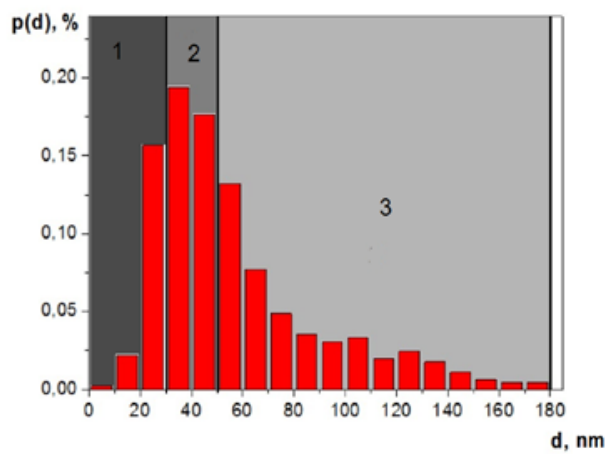

(b)

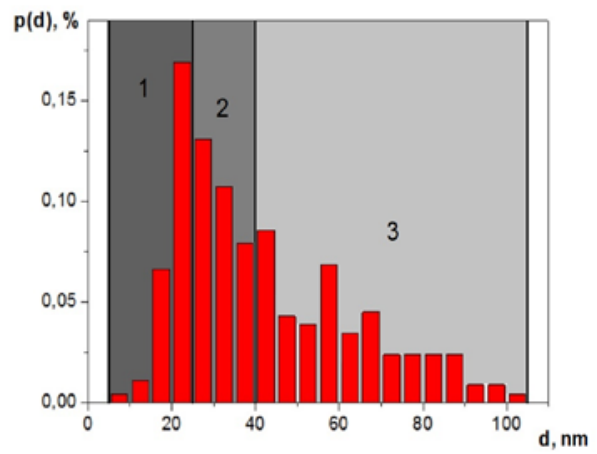

(d)

Figure 2. TEM images of $\mathrm{Ni} / \mathrm{CaO}$ catalyst nanoparticles: before (a) and after (c) reduction and the histogram of these nanoparticles size distribution before (b) and after (d) reduction of the catalyst.

Fig. $2 \mathrm{~b}$ shows the distribution of the nanoparticles of $\mathrm{Ni} / \mathrm{CaO}$ catalyst before reduction. It was indicated that it is a distribution of the mixture of nanoparticles of the active phase and the support. In accordance with the data presented in the table 1, it was divided into 3 regions. The region 1 (to $30 \mathrm{~nm}$ ) corresponds to the support nanoparticles distribution and the region $2(30-40 \mathrm{~nm})$ is related to the crystallites of the nickel nitrate. Region $3(40-180 \mathrm{~nm})$ probably is the distribution of the nickel nitrate nanoparticles agglomerates. It should also be noted that the region 3 may overlap with region 2 .

Several types of the nanoparticles are also present in the TEM image of reduced Ni/CaO catalyst (Fig. 2c). The dark spherical spots with light borders were attributed to the nickel nanoparticles [19] and the bright border around each nanoparticle to our opinion was nickel oxide layer formed in the air. The brighter spots apparently correspond to the nanoparticles of the support. The dispersion pattern was enhanced after reduction probably due to the disappearance of large agglomerates of nanoparticles of the active phase (Fig. 2c,d, Table 1). The distribution of the reduced Ni/CaO catalyst nanoparticles (Fig. 2d) may be divided into 3 regions in compliance with data presented in Table 1. Region 1 covers the distribution of single crystals of metallic nickel with the size close to $20 \mathrm{~nm}$. Region 2 is the distribution of nanoparticle of the support (CaO nanoparticles) and covers 25-40 nm region. Region $3(>40 \mathrm{~nm})$ is formed by the polycrystals of metallic nickel and their agglomerates, respectively.

\section{Characterization of MWCNTs Growth over the Ni/CaO Catalysts}

The TEM and SEM images of carbon nanotubes grown at the $\mathrm{Ni} / \mathrm{CaO}$ catalyst were shown in Fig. 3a, b. These MWCNTs can be classified into two types on the basis of the structures. One is multi-walled CNTs with relative small outer diameters $(\sim$ to $20 \mathrm{~nm})$ and twisted shape, indicating their high defect structure. Another type is the multi-walled CNTs with the bigger outer diameters and the smaller quantity of defects. At the ends of some MWCNTs, the metal nanoparticles were encapsulated. This indicates "tip-growth" mechanism of their growth [16]. From Fig. 2b, we can also observe that the amount of amorphous carbon impurities in the sample is small. 


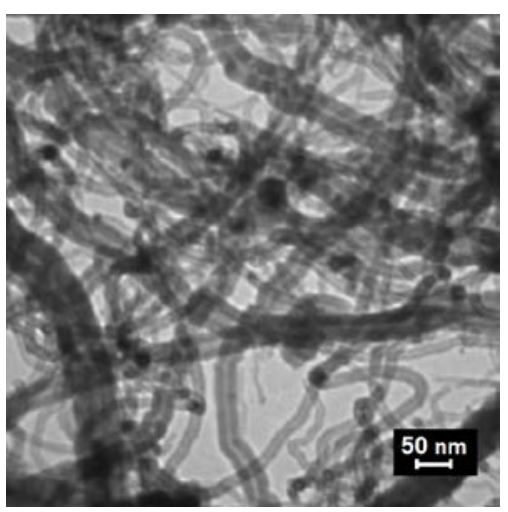

(a)

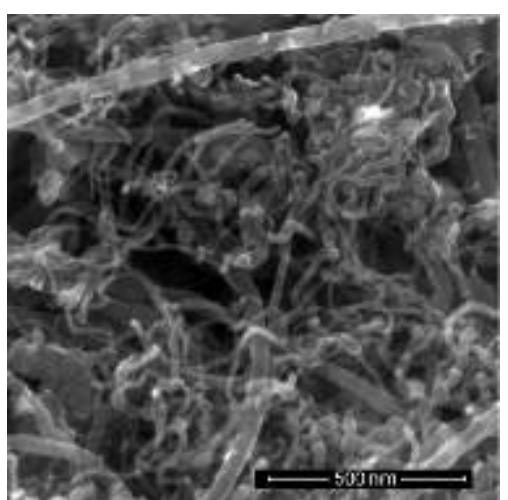

(b)

Figure 3. TEM (a) and SEM (b) images of MWCNTs grown on the Ni/CaO catalyst.

\section{Relationship between the Catalyst Sizes and Carbon Nanotubes Diameters}

Fig. 4a shows the Gaussian curves of size distribution of catalyst $\mathrm{Ni} / \mathrm{CaO}$ before and after reduction and of the external and internal diameters distribution of the MWCNTs grown at this catalyst. From the data presented we can observe that the distributions 3 (catalyst after reduction) and 4 (catalyst before reduction) overlap in the range $10-120 \mathrm{~nm}$. It is seen, that during the reduction, the dispersion of the active phase is slightly increased. Agglomerates of crystallites of nickel nitrate are fragmented into smaller nanoparticles that the later are converted to the metallic nickel.

The size distribution of the reduced catalyst nanoparticles (curve 3) is overlapped with the external diameter distribution of the MWCNTs (curve 2 overlapping range $15-80 \mathrm{~nm}$ ). However, it was not overlapped completely with the internal diameter distribution of the MWCNTs (curve 1, overlapping range $15-25 \mathrm{~nm}$ ). Thus, the size of catalyst nanoparticles determines the outer diameters of carbon nanotubes and in only some cases it defines internal diameters of the MWCNTs. In our previous study, we proposed the theory where the size of the metal nanoparticle determines the inner MWCNTs diameter proving the strong metal-support interaction that results in the "tip-growth" mechanism of their growth. The formation of MWCNTs by "base-growth" mechanism occurs in the case of a weak interaction between the support and active phase metal [20]. Thus, the MWCNTs shown in Fig. 3 in our opinion are grown mostly by "tip-growth" mechanism. It is confirmed by the TEM image (Fig. 3a) where the metal nanoparticles were found at the end of the nanotubes. According to Ratkovic et al., the "tip-growth" mechanism of the MWCNTs indicates the week metal-support interaction [21].

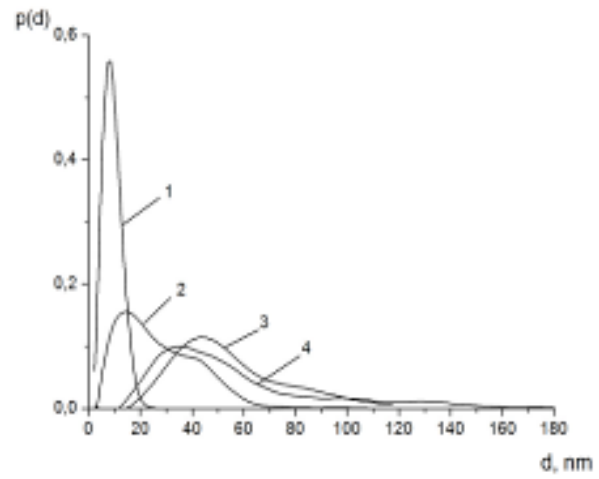

(a)

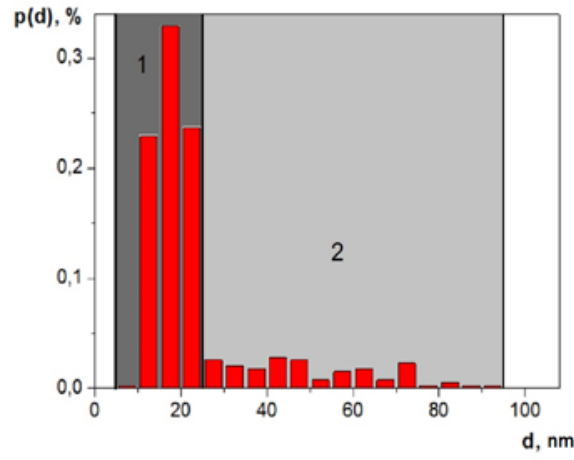

(b)

Figure 4. The Gaussian fits of the distributions (a) of: 1 - internal diameters of MWCNTs grown on the Ni/CaO catalyst; 2 - external diameters of MWCNTs grown on the Ni/CaO catalyst; 3 - Ni/CaO catalyst nanoparticles after reduction; 4 - Ni/CaO catalyst nanoparticles before reduction; and (b) the histogram distribution of the external diameters of the MWCNTs grown on the $\mathrm{Ni} / \mathrm{CaO}$ catalyst. 
Fig. 4b shows the external diameters distribution of MWCNTs grown on the Ni/CaO catalyst. Here the region 1 is the distribution of the first type of carbon nanotubes with diameters in the range of 5-25 nm (Fig. 3). Apparently, they were grown on the single-crystalline nickel nanoparticles of this size (Fig. $2 \mathrm{~d}$, region 1). Region 2 includes the distribution of MWCNTs with the diameters in range 25-95 $\mathrm{nm}$. We suppose that they are formed on polycrystalline agglomerated nanoparticles of metallic nickel, which corresponds to the distribution region 3 in Fig. 2 d.

\section{$3.1 \quad \mathrm{Ni} / \mathrm{CaCO}_{3}$ Catalyst}

\section{Characterization of the $\mathrm{Ni} / \mathrm{CaCO}_{3}$ Catalyst}

Fig. 5 displays the diffraction pattern of the catalyst $\mathrm{Ni} / \mathrm{CaCO}_{3}$ before and after reduction. Two crystallographic phases appeared at the diffraction pattern of a catalyst before reduction (curve 1). The diffraction peaks at $2 \theta=23,29,36,43,47$ and $49^{\circ}$ can be attributed to the $\mathrm{CaCO}_{3}$ and the peaks at $2 \theta=37$ and $43^{\circ}$ were assigned to the crystal planes of $\mathrm{NiO}$. During reduction of the catalyst in a hydrogen environment at $700^{\circ} \mathrm{C}$ the phase of $\mathrm{CaCO}_{3}$ decomposes to the $\mathrm{CO}_{2}$ and $\mathrm{CaO}(2 \theta=32,37,54$, 64 and $67^{\circ}$, curve 2). $\mathrm{NiO}$ at these conditions reduced to the metallic $\mathrm{Ni}\left(2 \theta=44\right.$ and $52^{\circ}$, curve 2$)$. Decomposition of the $\mathrm{CaCO}_{3}$ at relatively low temperature can be explained by the presence of metallic component [22]. It is known that calcium carbonate may begin to decompose at a temperature of $600{ }^{\circ} \mathrm{C}$. Accordingly, the presence of metallic nickel in the catalyst can result in complete conversion of $\mathrm{CaCO}_{3}$ to $\mathrm{CaO}$ already at $700{ }^{\circ} \mathrm{C}$.

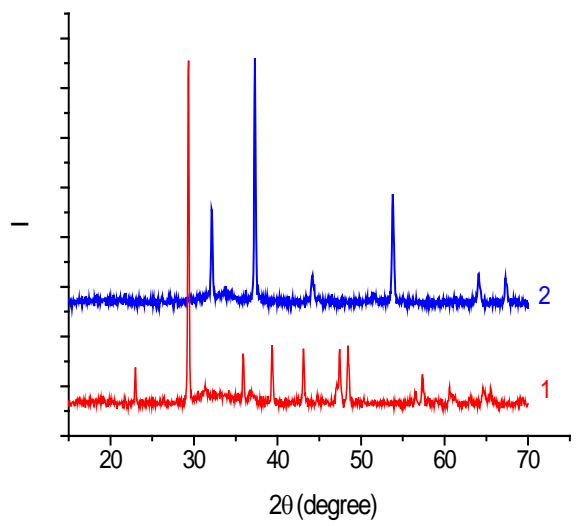

Figure 5. XRD patterns of $\mathrm{Ni} / \mathrm{CaCO}_{3}$ catalyst before (1) and after (2) reduction.

From the data presented in the table 2 we can see that the sizes of the single-crystalline nanoparticles of the active catalyst phase and support during the reduction of the $\mathrm{Ni} / \mathrm{CaCO}_{3}$ catalyst are decreasing. Thus, the dispersion of the $\mathrm{Ni} / \mathrm{CaCO}_{3}$ nanoparticles after reduction increases as in the case of the $\mathrm{Ni} / \mathrm{CaO}$ catalyst.

Table 2. Crystallite sizes of phases obtained by the EVA software for $\mathrm{Ni} / \mathrm{CaCO}_{3}$ catalyst before and after reduction.

\begin{tabular}{lccc}
\hline \multicolumn{2}{c}{ Before reduction } & \multicolumn{2}{c}{ After reduction } \\
\hline Phase & Size $(\mathrm{nm})$ & Phase & Size $(\mathrm{nm})$ \\
\hline $\mathrm{NiO}$ & 41 & $\mathrm{Ni}$ & $12-23$ \\
$\mathrm{CaCO}_{3}$ & $39-43$ & $\mathrm{CaO}$ & $33-39$ \\
\hline
\end{tabular}

Fig. 6a displays the TEM-image of the $\mathrm{Ni} / \mathrm{CaCO}_{3}$ catalyst before reduction. It is seen that the size of the particles formed during the preparation of the catalyst was exceeding $200 \mathrm{~nm}$. From Fig. $6 \mathrm{~b}$ we can observe the nanoparticles of the $\mathrm{Ni} / \mathrm{CaCO}_{3}$ catalyst obtained after reduction. Some of these particles are spherical and have the bright borders. These particles were attributed to the Ni-nanoparticles. The 
brighter spots were assigned to the nanoparticles of $\mathrm{CaO}$. It can also be seen from the Fig. $6 \mathrm{~b}$ that some of the nanoparticles form agglomerates. The distribution of the nanoparticles of reduced $\mathrm{Ni} / \mathrm{CaCO}$ catalyst is shown in Fig. 6c. According to the data presented in Table 2, the single crystals of nickel and their agglomerates distributions belong to Region 1 and Region 2 respectively. The distribution of the $\mathrm{CaO}$ crystallites was attributed to the Region 3 that overlaps with Region 2.

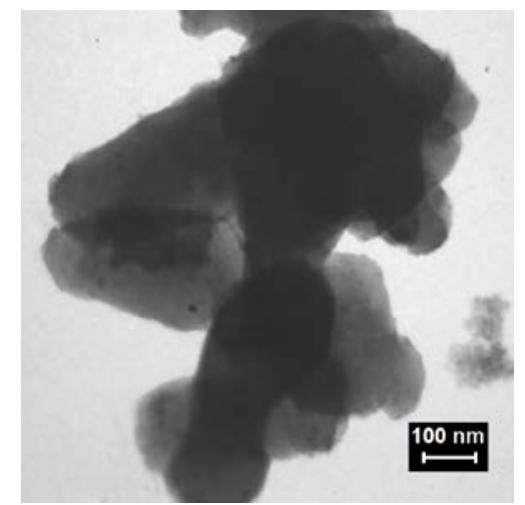

(a)

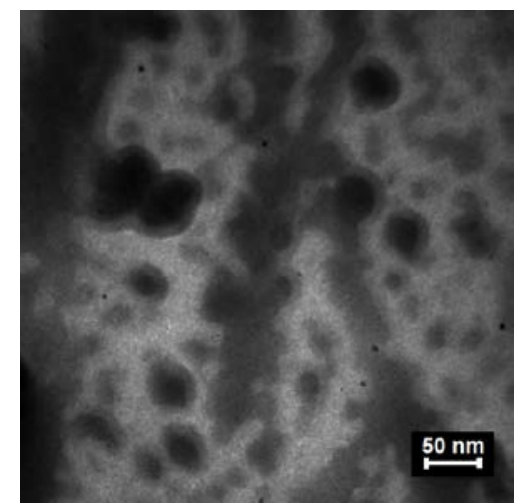

(b)

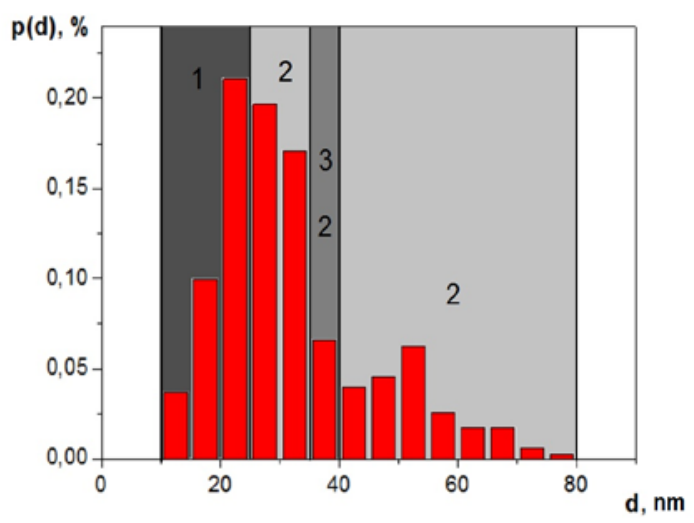

(c)

Figure 6. TEM images of $\mathrm{Ni} / \mathrm{CaCO}_{3}$ catalyst nanoparticles before (a) and after (b) reduction and the histogram of $\mathrm{Ni} / \mathrm{CaCO}_{3}$ catalyst nanoparticles size distribution after reduction (c).

\section{Characterization of Deposited Carbon Material}

Fig. 7a presents the TEM image of the MWCNTs grown on the $\mathrm{Ni} / \mathrm{CaCO}_{3}$ catalyst. From TEM observation, it is noticeable that carbons grown on this catalyst are heterogeneous in morphology and contain impurities of the amorphous carbon. This carbons can be classified into multi-walled carbon nanotubes and filamentous carbons with a chain-like structure [23, 24]. The walls of the chain-like carbon fibers $(\mathrm{CCF})$ are of uneven structures and the hollows of these carbon fibers are divided into many cells. Chain-like carbons fibers contain some cells filled with the metallic particle. The metal particles were found also at the tips of the carbon nanotubes. The presence of the carbons of the mentioned structure was confirmed by the SEM image shown in Fig. 7b.

\section{The Relationship between the Catalyst Sizes and Carbon Nanotubes Diameters}

The Gaussian curves of diameter distribution of the carbons (MWCNTs and CCF) grown on the $\mathrm{Ni} / \mathrm{CaCO}_{3}$ catalyst and size distribution of $\mathrm{Ni} / \mathrm{CaCO}_{3}$ catalyst nanoparticles were shown in Fig. 8. It is observed that the curve of the nanoparticles catalyst distribution (curve 2) partially cover both the curve of the internal (curve 1) and the external (curve 3) carbons diameters. 


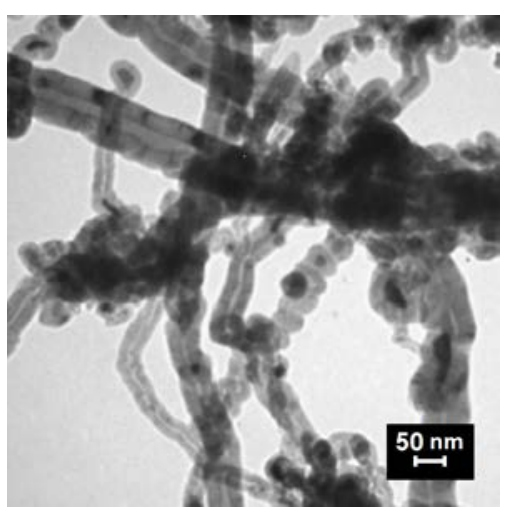

(a)

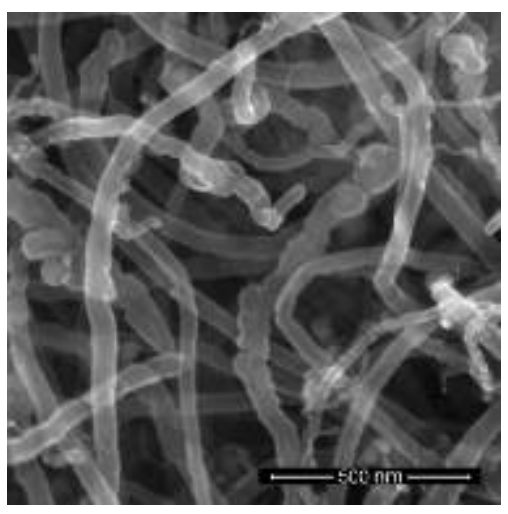

(b)

Figure 7. TEM (a) and SEM (b) images of MWCNTs grown on the $\mathrm{Ni} / \mathrm{CaCO}_{3}$ catalyst.

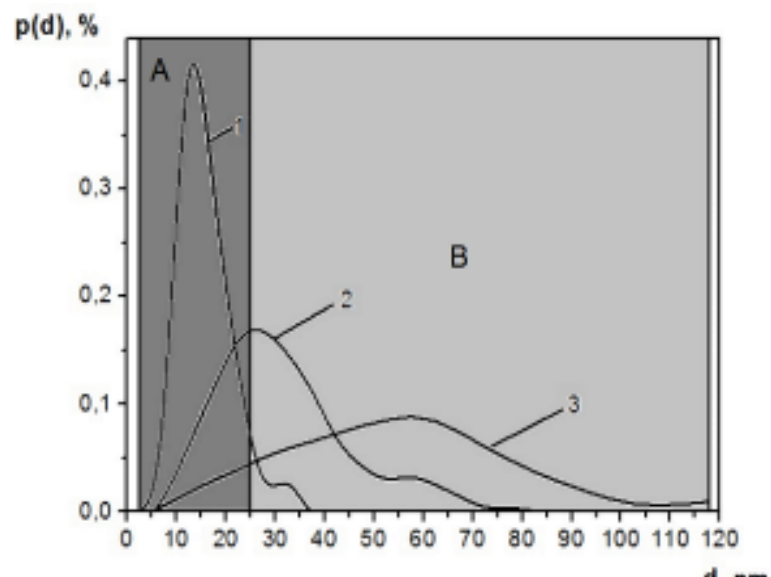

Figure 8. The Gaussian fits of the distributions of 1 - inner diameters of the MWCNTs, 2 - nanoparticles of the reduced catalyst; 3 - outer diameters of the MWCNTs.

In this case, the size of the metal nanoparticle determines the outer MWCNTs diameters. Thus, the one-half of the carbons presented in Fig 7 grow by the "tip-growth", the other by the "base-growth" mechanism [20]. Distributions area at the Fig. 8 was divided into two regions, based on the data presented in Fig. 6c and Table 2. Region A corresponds to the diameters distribution of carbons growing on single crystals of nickel. The Region B corresponds to the diameters distribution of mix of MWCNTs and CCF grown on the agglomerated nanoparticles of nickel. The size of single crystals of nickel defines inner and outer diameters of carbons (Region A) and size of the agglomerated nickel nanoparticles determines generally the outer diameters of the nanotubes (Region B). Therefore, carbon nanotubes formed on the nickel single crystals were grown both by "tip-growth" and by "base-growth" mechanism. The carbons formed on polycrystalline metal nanoparticles were grown predominately by the "tipgrowth" mechanism. It can be explained by predominantly weak metal-support interaction [21].

The diameters distribution of the carbons covers a wider range than the size distribution of particles of reduced $\mathrm{Ni} / \mathrm{CaCO}_{3}$ catalyst. It can be explained by aggregation of nanoparticles of nickel during the synthesis of carbon nanotubes.

The statistical data obtained from all distributions were summarized in Table 3. The MWCNTs obtained on the $\mathrm{Ni} / \mathrm{CaO}$ and $\mathrm{Ni} / \mathrm{CaCO}_{3}$ catalysts demonstrated the inner and outer diameters of $9.2 \pm 3.4,24.1 \pm 15.4$ and $15.9 \pm 5.3,56.2 \pm 23.0 \mathrm{~nm}$ (average diameter \pm standard deviation), respectively. This result shows that using the $\mathrm{CaO}$ support decreases the inner and outer diameters of the MWCNTs. 
Table 3. The statistical data obtained from the MWCNTs diameters distributions and total size distributions of the catalysts.

\begin{tabular}{|c|c|c|}
\hline Parameter & $\begin{array}{l}\text { Mean size or diameter } \\
(\mathrm{nm})\end{array}$ & Standard deviation $(\mathrm{nm})$ \\
\hline $\mathrm{Ni} / \mathrm{CaO}$ catalyst nanoparticles before reduction (total) & 56.6 & 32.9 \\
\hline $\mathrm{Ni} / \mathrm{CaO}$ catalyst nanoparticles after reduction (total) & 41.7 & 20.9 \\
\hline internal diameters of MWCNTs grown on $\mathrm{Ni} / \mathrm{CaO}$ catalyst & 9.2 & 3.4 \\
\hline external diameters of MWCNTs grown on $\mathrm{Ni} / \mathrm{CaO}$ catalyst & 24.1 & 15.4 \\
\hline $\mathrm{Ni} / \mathrm{CaCO}_{3}$ catalyst nanoparticles after reduction (total) & 32.2 & 13.7 \\
\hline internal diameters of MWCNTs grown on $\mathrm{Ni} / \mathrm{CaCO}_{3}$ catalyst & 15.9 & 5.3 \\
\hline external diameters of MWCNTs grown on $\mathrm{Ni} / \mathrm{CaCO}_{3}$ catalyst & 56.2 & 23.0 \\
\hline
\end{tabular}

\section{Conclusions}

The role of support in the Ni-containing catalysts prepared by impregnation method for the formation of MWCNTs from the CCVD of ethylene was investigated. The experimental results suggested that using the $\mathrm{Ni} / \mathrm{CaO}$ catalyst resulted in the formation of the two structural types of the MWCNTs with the total mean diameter \pm standard deviation of the $24 \pm 15 \mathrm{~nm}$. One type is MWCNTs with outer diameters lying in the range of 5-25 nm. It was found that these MWCNTs are formed on the singlecrystalline nickel nanoparticles of the same size. The MWCNTs with outer diameters of 25-95 nm were attributed to another structural type. It was determined that they are formed on the polycrystalline nanoparticles of metallic nickel with the corresponding size. Using the $\mathrm{Ni} / \mathrm{CaCO}_{3}$ catalyst results in the formation of the combination of the MWCNTs and CCF with the total mean diameter \pm standard deviation of the $56 \pm 23 \mathrm{~nm}$. The main factors that determine the diameters distribution and the morphology of the MWCNTs are the chemical transformation during preparing, reduction of the catalyst and carbon nanotubes synthesis. The chemical transformation during the reduction of the $\mathrm{Ni} / \mathrm{CaCO}_{3}$ results in the formation of the agglomerated nanoparticles on which the different types of carbons form.

The carbons obtained at the both catalysts are grown preferentially by the "tip-growth" mechanism. It was shown that "tip-growth" mechanism takes place when the MWCNTs are grown on the polycrystalline $\mathrm{Ni}$ nanoparticles. At the single-crystalline nickel nanoparticles, the formation of the MWCNTs is possible either by the "tip-growth" or "base-growth" mechanism.

\section{References}

1. R. H. Baughman, A. A. Zakhidov, W. A. Heer, "Carbon nanotubes-the route toward applications", Science, vol. 297, pp. 787-792, 2002.

2. L. Q. Liu, W. J. Ma, Z. Zhang, "Macroscopic carbon nanotube assemblies: Preparation, properties, and potential applications", Small, vol. 7, pp. 1504-1520, 2011.

3. M. Escobar, M. S. Moreno, R. J. Candal, M. C. Marchi, A. Caso, P. I. Polosecki, G. H. Rubiolo, S. Goyanes, "Synthesis of carbon nanotubes by CVD: Effect of acetylene pressure on nanotubes characteristics", Appl. Surf. Sci. vol. 254, pp. 251-256, 2007.

4. A. Okita, Y. Suda, A. Oda, J. Nakamura, A. Ozeki, K. Bhattacharyya, H. Sugawara, Y. Sakai, "Effects of hydrogen on carbon nanotube formation in $\mathrm{CH}_{4} / \mathrm{H}_{2}$ plasmas", Carbon, vol. 45, pp.1518-1526, 2007.

5. T. Somanathan, A. Pandurangan, "Towards the low temperature growth of uniform diameter multi walled carbon nanotubes by catalytic chemical vapour deposition technique", Nano-Micro Letters, vol. 2, pp. 204-212, 2010 .

6. H. Igarashi, H. Murakami, Y. Murakami, S. Maruyama, N. Nakashima, "Purification and characterization of zeolite-supported single-walled carbon nanotubes catalytically synthesized from ethanol", Chem. Phys. Lett., vol. 392, pp. 529-532, 2004.

7. I. Schmidt, A. Boisen, E. Gustavsson, K. Ståhl, S. Pehrson, S. Dahl, A. Carlsson, C. J. H. Jacobsen, "Carbon nanotube template growth of mesoporous zeolite single crystals", Chem. Mater., vol. 13, pp. 4416-4418, 2001. 
8. C.T. Wirth, B. C. Bayer, A. D. Gamalski, S. Esconjauregui, R. S. Weatherup, C. Ducati, C. Baehtz, J. Robertson, S. Hofmann, "The Phase of Iron Catalyst Nanoparticles during Carbon Nanotube Growth", Chem Mater. vol. 24, (2012) pp. 4633-4640.

9. K. Hernadi, A. Fonseca, J.B. Nagy, D. Bernaerts, A.A. Lucas, "Fe-catalyzed carbon nanotube formation", Carbon, vol. 34, pp. 1249-1257, 1996.

10. M. Ran, W. Chu, Y. Liu, D. Liu, C. Zhang, J. Zheng, "Doping effects of manganese on the catalytic performance and structure of NiMgO catalysts for controllabe synthesis of multi-walled carbon nanotubes", Journal of Energy Chemistry, vol. 23, pp. 781-788, 2014.

11. S.A. Shokry, A.K. El Morsi, M.S. Sabaa, R.R. Mohamed, H.E. El Sorogy, "Study of the productivity of MWCNT over Fe and Fe-Co catalysts supported on $\mathrm{SiO}_{2}, \mathrm{Al}_{2} \mathrm{O}_{3}$ and $\mathrm{MgO}$ ", Egyptian Journal of Petroleum, vol. 23, pp. 183-189, 2014.

12. E. Piperopoulos, S. Santangelo, M. Lanza, G. Faggio, G. Messina, S. Galvagno, A. Pistone, C. Milone, "Synthesis and analysis of multi-walled carbon nanotubes/oxides hybrid materials for polymer composite", Diam. Relat. Mater., vol. 20, pp. 532-537, 2011.

13. H. Kathyayini, N. Nagarajua, A. Fonseca, J.B. Nagy, "Catalytic activity of Fe, Co and Fe/Co supported on Ca and $\mathrm{Mg}$ oxides, hydroxides and carbonates in the synthesis of carbon nanotubes", Journal of Molecular Catalysis A: Chemical, vol. 223, pp. 129-136, 2004.

14. I. Yudanov, G. Pacchioni, K. Neyman, N. Rosch, "Systematic Density Functional Study of the Adsorption of Transition Metal Atoms on the $\mathrm{MgO}(001)$ Surface", J. Phys. Chem. B., vol.101, pp. 2786-2792, 1997.

15. S.C. Davis, K.J. Klabunde, "Unsupported small metal particles: preparation, reactivity, and characterization", Chem. Rev., vol. 82, pp. 153-208, 1982.

16. R.T.K. Baker, "Catalytic growth of carbon filaments", Carbon, vol. 27, pp. 315-323, 1989

17. I.K. Song, Y.S. Cho, G.S. Choi, J.B. Park, D.J. Kim, "The growth mode change in carbon nanotube synthesis in plasma-enhanced chemical vapor deposition", Diamond Relat. Mater., vol. 13, pp. 1210-1213, 2004.

18. C. Bower, O. Zhou, W. Zhu, D.J. Werder, S. Jin, "Nucleation and growth of carbon nanotubes by microwave plasma chemical vapor deposition", Appl. Phys. Lett., vol. 77, pp. 2767-2769, 2000.

19. D. Shindo, K. Hiraga, "High-Resolution Electron Microscopy for Materials Science" Tokyo: Springer, 1998.

20. N.V. Lemesh, P.E. Strizhak, A.I. Tripolsky, "Effect of the support of nickel-containing catalysts for the synthesis of carbon nanotubes on their internal and external diameters", Teoret. Exper. Chem., vol. 49, pp. 121$125,2013$.

21. S. Ratkovic, Dj. Vujicic, E. Kiss, G. Boskovic, O. Geszti, "Different degrees of weak metal-support interaction in $\mathrm{Fe}-(\mathrm{Ni}) / \mathrm{Al}_{2} \mathrm{O}_{3}$ catalyst governing activity and selectivity in carbon nanotubes' production using ethylene", Materials Chemistry and Physics, vol. 129, pp. 398-405, 2011.

22. T.C. Schmitt, A.S. Biris, D.W. Miller, A.R. Biris, D. Lupu, S. Trigwell, Z.U. Rahman "Analysis of effluent gases during the CCVD growth of multi-wall carbon nanotubes from acetylene", Carbon, vol. 44, pp. 2032-2038, 2006.

23. M.A. Ermakova, D.Y. Ermakov, A.L. Chuvilin, G.G. Kuvshinov, "Decomposition of methane over iron catalysts at the range of moderate temperatures: the influence of structure of the catalytic systems and the reaction conditions on the yield of carbon and morphology of carbon filaments", J. Catal., vol. 201, pp. 183-197, 2001.

24. Ch. Laurent, A. Peigney, A. Rousset, "Synthesis of carbon nanotube-Fe- $\mathrm{Al}_{2} \mathrm{O}_{3}$ nanocomposite powders by selective reduction of different $\mathrm{Al}_{1.8} \mathrm{Fe}_{0.2} \mathrm{O}_{3}$ solid solutions", J. Mater. Chem., vol. 8, pp. 1263-1272, 1998. 